\title{
HIV and HBV Seroprevalence in Volunteer Blood Donors in Lubumbashi
}

\author{
Kabamba N. Michel ${ }^{1 *}$, Bwana K. Ignace ${ }^{2}$, Kilolo N.U. Elie ${ }^{2}$, Kalonji C. Deddy ${ }^{3}$, Kabyla I. \\ Benjamin 4 , Luboya N. Oscar ${ }^{4}$ \\ ${ }^{1}$ Department of Public Health, University of Kamina, Kamina, Democratic Republic of Congo \\ ${ }^{2}$ Department of Obstetrics and Gynecology, University of Kamina, Kamina, Democratic Republic of Congo \\ ${ }^{3}$ Department of Pediatrics, University of Kamina, Kamina, Democratic Republic of Congo \\ ${ }^{4}$ Department of Public Health, University of Lubumbashi, Lubumbashi, Democratic Republic of Congo
}

Received: October 07, 2015; Accepted: October 30, 2015; Published: November 25, 2015

*Corresponding author: Kabamba Nzaji Michel, Department of Public Health, University of Kamina, Kamina, Democratic Republic of Congo, Tel: +002-4397-8467-432; E-mail: michelnzaji@yahoo.fr

\begin{abstract}
Absract
Background: This work aimed to determine the prevalence of infectious markers of HBV and HIV among blood donors from Lubumbashi to define a policy for the future to improve their selection in order to optimally reduce the risk of transmission of infection through the blood transfusion.

Methods: For this purpose, a retrospective cross-sectional descriptive study was conducted among volunteer blood donors of the Provincial Blood Transmission Center (CPTS) of Lubumbashi, in the Democratic Republic of Congo during the period going from $1^{\text {st }}$ January to $31^{\text {st }}$ December 2014. The blood collections were made into two cabins (fixed and mobile).
\end{abstract}

Results: The results of our epidemiological investigation showed that in the year 2014, among 440 blood donors, the prevalence of HIV, HBsAg, was of $2.3 \%$, and $9.3 \%$ respectively. The marker of hepatitis B was the most encountered objective in our study.

The prevalence of HBsAg was higher in the first donated blood donors, that is, $17.0 \%$ compared to previous donors or $4.2 \%, 9.4 \%$ of male donors also had a positive result against $8.3 \%$ of female

Conclusion: The hepatitis B virus remains a major concern for blood recipient. For good blood safety, a particular emphasis must be put onto the pre-selection of donate blood donors' candidates and in supplying these viral markers screening tests.

Keywords: Prevalence; Hepatitis B; HIV; Volunteer; Blood donor

\section{Introduction}

Blood transfusion is a medical therapeutic act, but it also creates the risk of blood transmitting infectious agents in recipients despite advances in blood safety. Therefore, it is essential to detect these infectious agents to prevent transmission. Routine screening for Human Immunodeficiency Virus (HIV), Hepatitis B Virus (HBV), Hepatitis C Virus (HCV) and Treponema pallidum on all donated blood and blood collection are among the four major elements of the strategy adopted by WHO in blood safety [1].
In fact, in developing countries or countries of economy transition, many people die because of the lack of safe blood, even in some urban healthcare facilities [2]. Blood transfusions can save lives and improve health, but millions of patients did not timely access to safe blood, no reliable blood donors. Blood transfusions are an essential aspect of health care, and everyone should have fair access to safe blood.

Two billion people worldwide have serologic evidence of HBV infection current or past, and 350 million are chronically infected and at risk of developing liver disease related to HBV. Approximately 15-40\% of chronically infected patients develop cirrhosis, progressing to liver failure and / or hepatocellular carcinoma. Infection with HBV is causing between 500,000 to $1,200,000$ deaths each year. HBV prevalence varies significantly in different regions of the world [3]. Let's consider the SubSaharan Africa, the prevalence of hepatitis B among blood donors ranges from 9.2\% in the Democratic Republic of Congo and 10.7\% in Cameroon [4]. In late 2010, UNAIDS estimated that 34 million (31.6 to 35.2 million) people living with HIV worldwide, an increase of $17 \%$ as compared to the year 2001 which 4 million are attributable to blood transfusions or other medical injections. Today, HIV transmission through that path is still relevant for the majority of inhabitants of the planet [5].

In fact, in this part of the world, that is to say, the sub-Saharan Africa, two factors account for the difficulties encountered to achieve optimal blood safety, the existence in the population of a high frequency of various infections, some of which are transmitted by blood transfusion and still insufficient proportion of voluntarily donors are the safest group [6].

Therefore, the objective of this study has been to determine the prevalence of HBV and HIV infection among volunteer donors of the Provincial Blood Transfusion Center of Katanga, to define for the future a policy to improve their selection, to reduce significantly the risk of transmitting infections through blood transfusion. 


\section{Materials and Methods}

\section{Study site}

This retrospective study of volunteer blood donors during the period from $1^{\text {st }}$ January to $31^{\text {st }}$ December 2014 was conducted at the Provincial Blood Transfusion Center (CPTS) of Lubumbashi (Democratic Republic of Congo). The blood collection was performed into two cabins (fixed and mobile).

\section{Study design}

It is a descriptive cross-sectional retrospective study of serum markers of HBV and HIV. Our target population consists of all voluntary blood donors of this Provincial Blood Transfusion Center (CPTS). The sample consisted of 440 donors, randomly selected using a simple random sampling? Serodiagnosis on each blood donation was made using commercial kits (Determine TM HBsAg, Inverness Medical Japan Ltd for HBV and HIV-TM, Determine 1/2 for HIV).

The collected data were coded, entered, processed and analyzed using SPSS 19. Descriptive analysis software was achieved through the calculations of proportions for categorical variables and the different frequency comparisons were encrypted using Pearson's Chi-square test and Fisher test when necessary. We set the statistical significance and the $p$-value $<0.05$.

\section{Results}

The data of 440 blood donors were included in this analysis. These blood donors were selected from the donors who voluntarily attending the fixed and mobile cabine for donations in the period from $1^{\text {st }}$ January to $31^{\text {st }}$ December 2014 . The provincial transfusion center organizes campaigns for blood donation by the active search for blood donors either in their building (fixed cabin) or by going to the people with the mass awareness.

The results as presented in Chart 1 shows that $88.2 \%$ of donors were aged between 19 and 45 years, only $1.6 \%$ had lower age than or equal to 18 years. The average age of donors was $32 \pm 10$ years ranging from 17 to 66 years.

It is apparent from Chart 2 that $60 \%$ of donors had made at least one gift against $40 \%$ of donors who were at first donation.

The Chart3 shows that the seroprevalence of HBsAg was 9.3\% and $2.3 \%$ for the one of anti-HIV among volunteer donors.

Considering the variable seroprevalence of HIV, HBV and sex, $8.3 \%$ of female donors were positive for HIV against $1.7 \%$ male donors. And this difference was statistically significant $(p=0.04)$. Regarding hepatitis $B$, this chart shows that male donors were most affected (9.4\%) against $8.3 \%$ of female donors, although this difference is not statistically significant (Chart 4).

HIV prevalence is highest (2. 3\%) in the age group ranging from 19-45 years, it is higher for HBV (17. 8\%) for donors over 45 year seven if this difference is not statistically significant (Chart 5).

However, the Chart 6 shows that $17.0 \%$ of HBV positive new donors HBV against $4.2 \%$ among former donors and this difference were statistically significant $(p<0.0001)$. New donors were mostly affected by HIV (4.0\%) than older even if the difference is not statistically significant $(p=0.10)$.

\begin{tabular}{|l|l|l|}
\hline Chart 1: Distribution of donor age. \\
\hline Age in years & Number & Percent \\
\hline$\leq 18$ & 7 & 1.6 \\
\hline $19-45$ & 388 & 88.2 \\
\hline$>45$ & 45 & 10.2 \\
\hline Total & $\mathbf{4 4 0}$ & $\mathbf{1 0 0}$ \\
\hline
\end{tabular}

\begin{tabular}{|l|l|l|}
\hline \multicolumn{2}{|l|}{ Chart 2: Distribution of donors according to their categories. } \\
\hline Category of donors & Number & Percent \\
\hline Former & 264 & 60 \\
\hline New & 176 & 40 \\
\hline Total & $\mathbf{4 4 0}$ & $\mathbf{1 0 0 . 0}$ \\
\hline
\end{tabular}

Chart 3: HIV and HBV seroprevalence in blood donors.

\begin{tabular}{|l|l|l|l|l|}
\hline \multirow{2}{*}{ Result } & HIV & HBV \\
\cline { 2 - 5 } & Number & Percent & Number & Percent \\
\hline Positive & 10 & 97.7 & 41 & 9.3 \\
\hline Negative & 430 & 2.3 & 399 & 90.7 \\
\hline Total & 440 & 100 & 440 & 100 \\
\hline
\end{tabular}

Chart 4: HBV and HIV seroprevalence depending on donor's sex.

\begin{tabular}{|l|l|l|l|l|}
\hline \multirow{2}{*}{ Sex } & \multicolumn{2}{|l|}{ HIV } & HBV \\
\cline { 2 - 5 } & Positive & Negative & Positive & Negative \\
\hline Female & $3(8.3 \%)$ & $33(91.7 \%)$ & $3(8.3 \%)$ & $33(91.7 \%)$ \\
\hline Male & $7(1.7 \%)$ & $397(98.3 \%)$ & $38(9.4 \%)$ & $366(90.6 \%)$ \\
\hline Total & 10 & 430 & 41 & 399 \\
\hline $\begin{array}{l}\text { OR and 95\% } \\
\text { CI }\end{array}$ & $\mathbf{5 . 1 6}[1.27$ to 20.87$]$ & $\mathbf{0 . 8 8}[\mathbf{0 . 2 6}$ to 2.99] \\
\hline p-value & $\mathbf{0 . 0 4}$ & $\mathbf{0 . 9 3}$ & \\
\hline
\end{tabular}

Chart 5: HIV and HBV seroprevalence by age of blood donors.

\begin{tabular}{|l|l|l|l|l|}
\hline \multirow{2}{*}{ Age in years } & HIV & \multicolumn{3}{l|}{ HBV } \\
\cline { 2 - 5 } & Positive & Negative & Positive & Negative \\
\hline$\leq 18$ & $0(0.0 \%)$ & $7(100 \%)$ & $1(14.3 \%)$ & $6(85.7 \%)$ \\
\hline $19-45$ & $9(2.3 \%)$ & $379(97.7 \%)$ & $32(8.2 \%)$ & $356(91.8 \%)$ \\
\hline$>45$ & $1(2.2 \%)$ & $44(97.8 \%)$ & $8(17.8 \%)$ & $37(82.2 \%)$ \\
\hline p-value & $\mathbf{0 . 9 2}$ & & $\mathbf{0 . 1 0}$ & \\
\hline
\end{tabular}

\section{Discussion}

On socio-demographic terms, our study showed that the majority of donors $(91.8 \%)$ were male with a sex ratio of 10.6 and having age between 19-45 years. This finding is the same as that made by other authors in African studies and in our country, the DRC [7-9]. Indeed, Xavier in 1997, Kiemtoré in 1999, Tembely Guindo in 2002 and in 2003 had obtained the respective sex ratio of $5,8.7$, and $6.81[10]$. This masculine trend can be explained by the fact that men are more available than women for blood donation and a typical African belief stating that men are healthier and stronger than women [1]. Barriers to donate blood are also more likely in women than in men. 
Indeed, in some physiological states women cannot donate blood (women menstruating, pregnant or nursing women)[10].These factors may prevent many women to make a blood donation.

The overall HIV prevalence in this study was $2.3 \%$, it is lower than those reported in the literature concerning the city of Kisangani (4.7\%) [6] and north-eastern Democratic Republic of Congo (5.6\%), 5.5\% in Maiduguri, Nigeria $10.6 \%$ and $16.7 \%$ in Ethiopia [2]. This prevalence was higher in female volunteer donors and in the first donation.

The greater vulnerability of women vis-à-vis HIV is due to physiological and biological factors but also social, cultural and economic pressures that do not allow them to ensure their prevention [11]. For all these reasons, there is a feminization of the HIV/ AIDS highlights the limits of the emancipation of women in their sexuality and raised awareness programs to be implemented for them to acquire vital social and economic empowerment in the fight against passivity, fatalism and submission [11].

In the present study, the seroprevalence ofHBsAg was 9.3\% with predominance in the male sex (17.3\%), especially in first donation donors $(17.0 \%)$. HBV seroprevalence in this study is higher than that previously found in our country, 3.63\% in 2005 in Kinshasa [12], 3\% in Kisangani 2004 [6], and Morocco 2.81\% [13]; but this is less than that found in Kinshasa-West (9.2\%) [14], in 2001 and in other African study such Ghana 8.2\% [15]. This difference can be attributed to differences in methodologies. In fact, other authors have worked on the whole donor population (replacements and volunteers) while we worked solely on volunteer blood donors; moreover, some authors used confirmatory tests while we used the test for serology. The explanation we can advance for males compared to females is the role of socio-cultural characteristics presents only in men, such as circumcision. But other reasons may be a possibility of porting from birth with the mother-child transmission, blood transfusions and other ritual scarification.

\section{Conclusion}

Search for blood transmitting infectious agents from volunteer blood donors varies depending on the epidemiological context, but research of HIV, HBV, HCV, and T. pallidum is done systematically in all donors of blood.

The donor age ranged between 17 and 65 years with an age range of $19-45$ years majority comprising 261 donors is $59.3 \%$ with a male predominance $91.8 \%$ and $60.0 \%$ of donors Blood left at least two blood donations in 2014 and are considered as lapsed donors (regular).

The overall prevalence of infectious markers within the

\begin{tabular}{|c|c|c|c|c|}
\hline \multicolumn{5}{|c|}{ Chart 6: HIV seroprevalence and HBV depending on donors' categories. } \\
\hline \multirow{2}{*}{$\begin{array}{c}\text { Donors' } \\
\text { Categorya }\end{array}$} & \multicolumn{2}{|c|}{ HIV } & \multicolumn{2}{|c|}{ HBV } \\
\hline & Positive & Negative & Positive & Negative \\
\hline New & $7(4.0 \%)$ & $169(96.0 \%)$ & $30(17.0 \%)$ & $\begin{array}{c}146 \\
(83.0 \%)\end{array}$ \\
\hline Former & $3(1.1 \%)$ & $261(98.9 \%)$ & $11(4.2 \%)$ & $\begin{array}{c}253 \\
(95.8 \%)\end{array}$ \\
\hline Total & 10 & 430 & 41 & 399 \\
\hline OR and $95 \% \mathrm{CI}$ & \multicolumn{2}{|c|}{$3.60(0.92$ to 14.13$)$} & \multicolumn{2}{|c|}{$4.73(2.30$ to 9.72$)$} \\
\hline p-value & \multicolumn{2}{|c|}{0.10} & \multicolumn{2}{|c|}{$<0.0001$} \\
\hline
\end{tabular}

provincial blood center was $14.1 \%(n=62)$; the prevalence of antibodies to HIV, HBsAg, were $2.3 \%$, 9.3\%.

The prevalence of these infectious markers in our environment is sufficient to prove that the transfusion remains a public health problem in developing countries, in general, and especially in Lubumbashi; which justifies the systematic screening of all blood donors to reduce transfusion risk.

\section{References}

1. Rakotoniaina AI, Randriamanantany ZA, Ranaivosoa KHM, Andriambelo V, Fortuné H, Alson OAR, et al. Seroprevalence of HIV, HBV HCV and treponema pallidum among volunteer blood donors at the national blood transfusion centre in antananarivo from 1992 to 2010. The Medical Review of Madagascar. 2013;3(2):264-268.

2. Nzaji MK, Ilunga BK. A study of the prevalence of infectious markers in blood donors in rural areas. The case of Kamina hospital. Sante Publique. 2013;25(2):213-7.

3. Gastroentérologie OM de. Hépatite B. 2008;1-31.

4. Dominique N, Richard N, Aimé B, Pirsou P, Meli JM, Biwole S. HBs antigene prevalence in blood donors and the risk of transfusion of hepatitis $b$ at the central hospital of yaounde, cameroon. Open Journal of Gastroenterology. 2011;01(02):23-7.

5. PNUD. HIV / AIDS and human rights in the democratic republic of congo. 2013;7-108,

6. Batina A, Kabemba S, Malengela R. Infectious markers among blood donors in Democratic Republic of Congo (DRC). Rev Med Brux. 2007;28(3):145-149.

7. Lo BB, Meymouna M, Boulahi MA, Tew M, Sow A, Ba A, et al. Prevalence of serum markers of hepatitis $B$ and $C$ virus in blood donors of Nouakchott, Mauritania , Bull Soc Pathol Exot. 1999;92(2):83-4.

8. Zekeng L Kaptue L. HIV-1 serology and carrier state for HBs and HBe in blood donors at Yaounde University Hospital Center, Cameroon Ann Soc Belg Med Trop. 1990;70(1):49-53.

9. Mole S, Onana E, Biholong D. HIV and risk factors for the blood donors at the central hospital of Yaounde, Cameroon. Bull Soc Pathol Exot. 2011;104(3):226-231. doi: 10.1007/s13149-011-0163-3.

10. Diallo AH. Seroprevalence of co-infection by viruses B and C hepatitis among blood donors in Bamako," University of Bamako in 2006.

11. Fener $\mathrm{P}$, Criton C. Facteurs de risque de l ' infection à VIH / sida chez la femme Sommaire. 2007;1-62.

12. Kapila NG, Van Der Veken W, Ruppol S MA. S02-05 Apport De La Coopération Technique Belge Dans La Transfusion Sanguine En République Démocratique Du Congo De 2002 À 2004. Transfus Clin Biol. 2005;12:1-41.

13. Elira-Dokekias A, Okandze-Elenga JP, DZia-Lepfoundzou APH. Prevalence of major viral markers in blood donors in Brazzaville City. Transfus gas. 2002;4-6.

14. Mbendi Nlombi C, Longo-Mbenza B, Mbendi Nsukini S, Muyembe Tamfum JJ, Situakibanza Nanituma H, Vangu Ngoma D. Prevalence of HIV and HBs antigen in blood donors. Residual risk of contamination in blood recipients in East Kinshasa, Democratic Republic of the Congo. Med Trop Mars. 2001;61(2):139-142.

15. Allain JP, Candotti D, Soldan K, Sarkodie F, Phelps B, Giachetti C, et al. The risk of hepatitis $B$ virus infection by transfusion in Kumasi, Ghana. Blood. 2003;101(6):2419-25. 